\title{
PENGALAMAN IBU BEKERJA DALAM MEMBERIKAN ASI EKSKLUSIF
}

\author{
Rusmala Dewi, Fitri Nuriya Santy \\ Akademi Keperawatan Panca Bhakti Bandar Lampung \\ Email : rusmala@pancabhakti.ac.id
}

\begin{abstract}
ABSTRAK
ASI eksklusif adalah pemberian ASI tanpa makanan dan minuman tambahan lain pada bayi berumur 0-6 bulan. Mulai usia 6 bulan bayi diberikan makanan pendamping ASI dan tetap diberikan ASI sampai usia bayi dua tahun. Ibu bekerja yang sedang menyusui tetap dapat memberikan ASI eksklusif pada bayinya. Tujuan penelitian ini adalah untuk mengetahui pengalaman ibu bekerja dalam memberikan ASI eksklusif. Metode penelitian ini menggunakan pendekatan penelitian fenomenologi, partisipan yang terlibat adalah 5 orang ibu bekerja yang memiliki bayi 6 sampai 36 bulan dan berada diwilayah Kelurahan Gedong Meneng Bandar Lampung. Hasil penelitian ini didapatkan 4 kategori tentang pengalaman ibu bekerja dalam memberikan ASI eksklusif yaitu pengetahuan ibu tentang ASI eksklusif dan ASI perah, motivasi ibu dalam pemberian ASI eksklusif, upaya yang dilakukan ibu dalam memberikan ASI eksklusif, dukungan keluarga dan dukungan tempat kerja dalam memberikan ASI eksklusif. Hasil penelitian ini dapat menjadi gambaran bagi tenaga kesehatan untuk dapat meningkatkan promosi kesehatan tentang ASI eksklusif ke berbagai tempat kerja dan diharapkan agar tempat kerja dapat memfasilitasi ibu menyusui untuk memberikan ASI eksklusif agar cakupan ASI eksklusif meningkat.
\end{abstract}

Kata kunci: ASI, Ibu bekerja, Pengalaman

\begin{abstract}
Exclusive breastfeeding is breastfeeding without additional food and drinks for babies for 0-6 months. Starting at the age of 6 months the baby is given complementary breast milk and is still breastfed until the age of the baby is two years old. Exclusive breastfeeding to the baby. The purpose of this study was to study the experience of working mothers in giving exclusive breastfeeding. The research method used phenomenological research, the participants involved were 6 working mothers who had babies 6 to 36 months and were in the Gedong Meneng Bandar Lampung Village. The results of this study found 5 categories of experiences of working mothers in giving exclusive breastfeeding, namely mother's knowledge of exclusive breastfeeding and milk, mother's motivation in exclusive breastfeeding, efforts made by mothers in giving exclusive breastfeeding, family support and workplace support in giving exclusive breastfeeding. The results of this study can be an illustration for health workers to be able to improve health promotion about exclusive breastfeeding to various workplaces and hope that workplaces can facilitate breastfeeding mothers to provide exclusive breastfeeding so that exclusive breastfeeding coverage increases
\end{abstract}

Keywords: Breastfeeding, working mother, experience 


\section{PENDAHULUAN}

Air Susu Ibu (ASI) adalah makanan bayi sampai usia dua tahun. Bayi usia $0-6$ bulan hanya diberikan ASI tanpa makanan atau minuman tambahan lain pada bayi berumur 06 bulan atau disebut dengan ASI eksklusif (Kemenkes, 2013). Mulai usia 6 bulan bayi diberikan makanan pendamping ASI dan tetap diberikan ASI sampai usia bayi dua tahun. Sesuai dengan rekomendasi World Health Organization (2003) tentang standar emas makan bayi yaitu menyusui bayi segera dalam 1 jam setelah lahir, pemberian ASI eksklusif, pemberian makanan pendamping ASI sejak usia bayi 6 bulan dan teruskan pemberian ASI sampai anak berusia dua tahun atau lebih.

Pemberian ASI eksklusif dapat menurunkan angka kematian bayi baru lahir. Menurut The World Health Report 2005, angka kematian bayi baru lahir di Indonesia adalah 20 per 1.000 kelahiran hidup. Sedangkan angka kematian balita sebesar 46 per 1.000 kelahiran hidup. Berdasarkan penelitian WHO tahun 2000 pada enam negara berkembang, resiko kematian bayi antara 9-12 bulan meningkat $40 \%$ jika bayi tersebut tidak disusui. Sementara pada bayi berusia dibawah dua bulan, angka kematian ini meningkat menjadi 48\%. (Roesli, 2008).

Menurut United Nations International

Children's Emergency Fund (UNICEF) (2012)
Cakupan ASI Eksklusif di dunia rata-rata sebesar 38\%. Di Negara berkembang termasuk negara Indonesia cakupan ASI Eksklusif secara nasional, cakupan bayi mendapat ASI eksklusif sebesar 61,33\%. Angka tersebut sudah melampaui target Renstra tahun 2017 yaitu 44\%. Persentase tertinggi cakupan pemberian ASI eksklusif terdapat pada Nusa Tenggara Barat (87,35\%), sedangkan persentase terendah terdapat pada Papua (15,32\%). Ada lima provinsi yang belum mencapai target Renstra tahun 2017 salah satunya di Provinsi Lampung cakupan ASI Eksklusif masih mencapai 32,21\% (Kemenkes, 2018).

Ibu bekerja mempunyai hak untuk tetap memberikan ASI pada bayinya, hal tersebut didukung oleh pemerintah dengan ditetapkannya Peraturan Menteri kesehatan RI (2013) Nomor 15 tentang tata cara penyediaan fasilitas khusus menyusui dan/ atau memerah ASI. Pada Pasal 3 tertuang bahwa pengelola tempat kerja harus mendukung program ASI eksklusif melalui penyediaan khusus untuk menyusui dan memerah ASI serta memberikan kesempatan pada ibu bekerja untuk memberikan ASI eksklusif atau memerah ASI selama bekerja. Oleh karena itu peneliti tertarik untuk mengetahui pengalaman ibu bekerja dalam memberikan ASI Eksklusif pada bayinya. 


\section{METODOLOGI}

Desain penelitian yang digunakan dalam penelitian ini adalah kualitatif. Tujuan penelitian ini adalah menggali tentang pengalaman ibu bekerja dalam memberikan asi eksklusif. Waktu penelitian yaitu bulan Juli - September 2018. Partisipan yang terlibat yaitu 5 orang ibu bekerja yang memiliki bayi 6 sampai 36 bulan dan berada diwilayah Kelurahan Gedong Meneng Bandar Lampung. Tehnik pengumpulan data dengan wawancara mendalam menggunakan alat bantu perekam suara.

\section{HASIL}

Penelitian ini menghasilkan empat kategori yang menggambarkan pengalaman ibu bekerja dalam memberika ASI eksklusif. Kategori tersebut yaitu pengetahuan ibu tentang asi eksklusif, ASI perah, motivasi ibu dalam pemberian ASI eksklusif, upaya yang dilakukan ibu dalam memberikan asi eksklusif, dukungan keluarga dan dukungan tempat kerja.

Pengetahuan ibu tentang ASI eksklusif yaitu pengertian asi eksklusif, manfaat ASI eksklusif, seperti dalam kutipan berikut:

“....asi eksklusif adalah memberikan asi saja tanpa diberikan makanan yang lain pada bayi, walaupun air...” (P1)

“... Semakin sering disusui, asi semakin banyak.." (P2)
“... dengan asi eksklusif bayi saya cerdas, enam bulan pertama bayi tidak pernah sakit, batuk pilek juga tidak, bayi saya nggak gendut, tapi kenceng, kalo dipegang mantep...” (P3)

“...ASI bagus untuk kekebalan tubuh, nutrisi terpenuhi, meningkatkan keceerdasan bayi..." (P5)

Pengetahuan ibu tentang ASI Perah ditunjukkan dalam kutipan berikut:

“... ambil asi di freezer, letakkan dikulkas bawah sampai cair, tinggal diambil dan letakkan dibotol kaca, tuangin disitu ada mangkok yang berisi air panas, trus kita ukur berapa kehangatannya..” (P1)

“... asi perah dari freezer ditarok kebawah sampai cair, dipanasin, kalo saya asi perah sudah saya tarok didalam plastik khusus yang bisa direndam pakai air panas untuk menghangatkan asi..." (P3)

Motivasi Ibu dalam Memberikan Asi Eksklsif yaitu: kelengkapan nutrisi dalam ASI, meningkatkan kedekatan dengan bayi, meningkatkan daya tahan tubuh bayi, meningkatkan kecerdasan bayi, seperti dalam kutipan berikut:

“... bayi itukan investasi, harapan saya kedepannya bayi tumbuh dengan baik, sehat dengan asi, lebih dekat, daya tahan tubuhnya kuat, dan pintar" (P1) 
“...Asi bermanfaat untuk kedekatan kita dengan bayi..” (P2)

“...nutrisi di asi lengkap untuk bayi 6 bulan, bayi yang dikasih asi daya tahan tubuhnya kuat.." (P4)

Upaya yang dilakukan ibu untuk dapat memberikan ASI eksklusif yaitu meningkatkan pengetahuan tentang ASI eksklusif dengan cara membaca buku, membaca artikel melalui internet, mengikuti grup di internet yang mendukung ASI eksklusif, meningkatkan asupan nutrisi, menghindari stres, ditunjukkan dalam kutipan berikut:

“...saya beli buku persiapan ibu hamil, pelekatan ibu menyusui sebelum melahirkan, setelah melahirkan saya tetap searching internet, saya ikut grup diinternet, disitu dibahas gimana caranya kita pro pada asi, kiat memperbanyak asi ... usia bayi 2 minggu saya mulai memompa asi pakai tangan..." (P1)

“... hari keenam saya mulai pumping dengan menggunakan tangan, pakai alat bantu jika telah mulai bekerja lagi...

kalau saya pumping di tempat kerja, saya berusaha untuk rilex dan saya kadang pumping sambil liat foto bayi saya, karena saya pernah baca kalau sedang pumping kita rilex dan memikirkan bayi dengan cara melihat foto bayi, maka produksi asi akan banyak, itu saya rasakan kalau saya rilex, kerasa kalau ASI yang keluar banyak...” (P3)

“... saya makan yang banyak supaya asi saya banyak, ... sempet saya stress lalu saya berusaha untuk gak stres karena saya yakin saya bisa kasih asi eksklusif. saya baca artikel, buka web dan ikut web yang mendukung dalam pemberian asi eksklusif..." (P4)

“...saya makan banyak supaya ASI berlimpah, saya makan sayur - sayuran, saya sering makan sayur katuk, bayam, pokoknya sayuran hijau, porsi lebih dibanyakin, minum air putih, jangan stres, pernah saya stres dan produksi ASI berkurang.., saya cari - cari di internet untuk informasi tentang ASI eksklusif, saya sempet beli satu buku ASI dan MPASI... , ...umur anak saya setahun dua bulan, pas lagi sibuk, kerjaan menumpuk, saya stres, trus ASI berkurang, lalu saya sadar kalo bener stres mempengaruhi produksi ASI, dari situ saya mulai berusaha untuk enjoy" (P5).

Dukungan Keluarga dalam Memberikan Asi Eksklusif yaitu dari suami, orang tua, mertua, seperti dalam kutipan berikut:

“... kalo saya sedang menyusui, trus saya butuh sesuatu untuk diambilkan, trus suami saya membantu mengambilkan keperluan saya...”(P1) 
“... keluarga mendukung saya untu menyusui seperti suami, ibu kandung saya, ibu mertua, ipar saya mendukung saya untuk memberikan asi eksklusif..."

“... saya nggak bisa nyusuin sendiri harus dibantu, karena saya nggak bisa ngangkat bayi saya dengan kedua tangan dikarenakan salah satu tangan saya sakit dan setelah diperiksa asam urat saya tinggi, jadi suami saya yang bantu angkat bayi saya dan tarok bayi dideket saya untuk disusui,,,, orang tua saya jauh, jadi orang tua saya hanya beberapa hari datang kerumah saya, lalu pulang ke kampung lagi..." (P3)

“...suami saya membantu saya dalam memberikan asi eksklusif, kalau saya pergi, saya tinggalin asi perah dan suami saya yang kasih asi perah ke bayi saya..." (P4)

“...pernah saya merasakan puting sedikt lecet diawal menyusui, sebenarnya ada perasaan malas untuk menyusui saat itu, tapi suami saya selalu mengingatkan kembali kalau saya jangan memikirkan diri sendiri, akhirnya saya tetap memberikan ASI pada bayi..."(P5)

Dukungan tempat kerja dalam memberikan ASI Eksklusif yaitu lingkungan, pimpinan tempat kerja, seperti yang ditunjukkan dalam cuplikan wawancara berikut: “...teman kerja mendukung saya untuk memompa asi, ... ruang kerja saya kan ada pintunya, jadi pada saat saya memompa, saya nggak kesulitan mencari tempat untuk memompa..." (P1)

“...pimpinan tempat saya bekerja mengizinkan saya untuk meluangkan waktu memompa asi..." (P3)

“...ditempat kerja belum ada ruang khusus menyusui.., tapi saya bisa memompa ASI diruangan kerja saya..., ... teman kerja saya mendukung saya dalam memberikan ASI eksklusif...” (P5)

\section{PEMBAHASAN}

Pengetahuan tentang ASI eksklusif dan ASI perah sangat diperlukan untuk ibu bekerja, agar ibu bekerja termotivasi untuk memberikan ASI eksklusif pada bayinya. Partisipan memiliki pengetahuan yang cukup tentang ASI eksklusif dan ASI perah, sehingga semua partisipan juga termotivasi untuk memberikan ASI eksklusif pada bayinya. Menurut Poedianto (2002) bahwa pengetahuan ibu yang tinggi akan meningkatkan kepercayaan diri ibu dan iu memiliki motivasi yang tinggi dalam menyusui bayinya. Sejalan dengan hasil penelitian Aksu, Kucuk, \& Duzgun (2011) bahwa pemberian edukasi menyusui pada ibu postpartum dapat meningkatkan pengetahuan ibu terhadap pemberian ASI eksklusif dan lamanya menyusui. 
Ibu bekerja penting untuk menberikan ASI eksklusif pada bayinya, karena manfaat yang didapatkan dalam memberikan ASI eksklusif berdampak bukan hanya kepada ibu dan bayi, tetapi juga berdampak pada tempat bekerja. Hal ini dikarenakan dengan diberikannya ASI eksklusif, maka bayi yang dimiliki oleh ibu bekerja akan tumbuh menjadi bayi yang sehat dan tidak mudah terserang penyakit. Sejalan dengan Ip, dkk (2007) bahwa bayi yang mendapatkan ASI berhubungan dengan penurunan resiko otitis media akut, infeksi saluran pernafasan, suddent infant death syndrome, nonspesifik gastroenteritis, necrotic enterocolitis.

Jumlah pekerja perempuan di Indonesia terus meningkat. Tahun 2008 proporsi pekerja perempuan mencapai 37,9\%. . Proporsi ini meningkat ditahun 2010 menjadi 38,58\%

(Bidang Ketenagakerjaan dan Ketransmigrasian, 2012). Data tersebut menunjukkan bahwa banyaknya perempuan yang bekerja, dan diantara perempuan yang bekerja tersebut merupakan ibu yang sedang menyusui.

Pemerintah telah mengatur tentang cuti persalinan selama tiga bulan pada Undang Undang Nomor 13 tahun 2003, sehingga ibu bekerja dapat memberikan hak bayinya untuk mendapatkan ASI eksklusif. Waktu yang diberikan adalah tiga bulan, kemudian tiga bulan berikutnya merupakan tantangan bagi ibu yang menyusui untuk tetap dapat memberikan ASI eksklusif pada bayinya sesuai dengan Undang - Undang Nomor 36 tahun 2009 pasal 128 bahwa setiap bayi berhak mendapatkan ASI eksklusif sejak dilahirkan selama 6 bulan kecuali atas indikasi medik.

Undang - Undang tersebut dikuatkan lagi dengan adanya Peraturan Daerah Provinsi Lampung nomor 17 tahun 2014 pasal 4 bahwa setiap bayi berhak mendapatkan ASI eksklusif sejak dilahirkan selama 6 bulan kecuali atas indikasi medis. Pemerintah daerah juga mengatur dalam promosi susu formula bayi di Peraturan Daerah Provinsi Lampung nomor 17 tahun 2014 pasal 18 bahwa setiap tenaga kesehatan dan penyelenggara fasilitas pelayanan kesehatan dilarang memberikan, menerima dan atau mempromosikan susu formula bayi dan/ atau produk bayi lainnya yang dapat menghambat program pemberian ASI eksklusif kecuali atas indikasi medis dan khusus. Pasal 18 ini juga terdapat larangan menyediakan pelayanan dibidang kesehatan atas biaya yang disediakan oleh produsen atau distributor susu formula bayi dan/ atau produk bayi lainnya.

Tenaga kesehatan dan penyelenggara fasilitas pelayanan kesehatan yang melakukan pelanggaran pada pasal 18 tersebut akan 
dikenakan sanksi administratif yang tertuang pada pasal 24 berupa teguran tertulis, peringatan tertulis, denda dan/ atau pencabutan izin usaha. Sanksi juga ditegaskan dalam Undang - Undang nomor 36 tahun 2009 pasal 200 bahwa setiap orang yang dengan sengaja menghalangi program pemberian ASI eksklusif terkena ancaman pidana berupa pidana penjara paling lama 1 tahun dan denda paling banyak 100.000.000 (seratus juta rupiah)..

Dukungan pemerintah tentang pemberian ASI eksklusif diharapkan sejalan dengan dukungan tempat kerja. Undang - Undang nomor 15 tahun 2013 mengatur tentang tata cara penyediaan fasilitas khusus menyusui dan atau memerah ASI. Pasal 18 bahwa pemerintah mengatur agar tempat kerja menyediakan dana untuk mendukung peningkatan pemberian ASI eksklusif dan dana tersebut dilarang bersumber dari produsen atau distributor susu formula bayi dan/ atau produk bayi lainnya.

Undang - Undang nomor 152013 Pasal 11 membuat standar peralatan ruang ASI di tempat kerja sekurang - kurangnya terdiri dari peralatan menyimpan ASI dan peralatan apendukung lainnya sesuai standar seperti lemari pendingin (refrigerator) untuk menyimpan ASI, gel pendingin (ice pack), tas untuk membawa ASI perahan (cooler bag) dan sterilizer botol ASI. Enam partisipan yang terlibat dalam penelitian ini membawa sendiri peralatan pendukung yaitu cooler bag, ice pack, botol ASI untuk ASI perah.

Partisipan mendapatkan dukungan dari suami, teman, serta tempat kerja. Menurut Fikawati \& Syafik (2010) dan Setiowati (2011) bahwa dukungan suami dan tempat kerja merupakan faktor eksternal yang dapat mempengaruhi proses pemberian ASI. Menurut Chen, Wu \& Chie (2006) bahwa kebijakan tempat kerja dalam memberikan dukungan pada ibu menyusui yang bekerja berpengaruh signifikan terhadap perilaku menyusui. Hal ini sejalan dengan hasil penelitian Amin, Said,

Sutan,Shah, Darus \& Shamsuddin (2011) bahwa ada hubungan antara ketidakberlanjutannya ASI eksklusif dengan tidak tersedianya fasilitas dan ruang menyusui.

Selain dukungan, upaya yang dilakukan ibu juga sangat penting untuk mendukung keberhasilan ASI eksklusif. Salah satu upaya yang dilakukan oleh partisipan penelitian ini adalah mencari kelompok yang mendukung ASI di jejaring sosial. Jejaring sosial adalah media yang digunakan oleh manusia untuk berinteraksi satu sama lain menggunakan teknologi internet atau jaringan komunikai mobil yang memiliki kecepatan akses tinggi bertujuan untuk memfasilitasi komunkasi, 
mempengaruhi dan berinteraksi dengan sejawat maupun audience public (Solis \& Breaenridge). Saat ini banyak kelompok di media sosial yang mendukung ibu menyusui. Kelompok tersebut memberikan motivasi pada ibu menyusui agar memberikan ASI eksklusif pada bayinya.

Upaya lain yang dilakukan Partisipan adalah dengan meningkatkan konsumsi makanan tambahan yang bertujuan untuk menambah jumlah dan kualitas ASI. Menurut Selasi (2011) bahwa penting sekali bagi ibu untuk cukup makan dan minum, tapi hal tersebut tidak membantunya dalam menghasilkan ASI jika bayinya tidak menyusu. Agar ibu dapat memproduksi ASI, bayinya harus menyusu sering dan mengeluarkan ASI. Payudaranya akan merespon dan memproduksi ASI sebanyak bayi mengeluarkannya dari payudara.

Tingkat stres ibu menyusui juga mempengaruhi keberhasilan ibu menyusui. Produksi air susu ibu sangat dipengaruhi oleh kejiwaan. Ibu yang selalu dalam keadaan gelisah, kurang percaya diri, rasa tertekan dan berbagai bentuk ketegangan emosional, akan dapat mempengaruhi proses menyusui bayinya. Pada ibu bekerja perasaan ibu yang sering muncul adalah kondisi dimana ibu bekerja harus meninggalkan rumah dalam waktu yang cukup lama 7 sampai 10 jam, menyebabkan ibu tidak dapat menyusui dengan langsung. Partisipan dalam penelitian ini (P4, P5) mengutarakan bahwa merasakan stres dan jika stres produksi ASInya berkurang.

Saat bayi menyusu, rangsangan sensorik dari puting dikirim ke otak, kemudian belakang kelenjar pituitari didasar otak mengeluarkan hormon oksitosin. Oksitosin masuk kedalam darah menuju payudara dan merangsang sel otot disekeliling alveoli berkontraksi. Kontraksi tersebut akan membuat ASI yang telah terkumpul didalam alveoli mengalir sepanjang duktus menuju puting. Reflek ini disebut dengan reflek oksitosin. Reflek oksitosin dipengaruhi oleh pikiran dan perasaan. Perasaan positif dapat membantu reflek oksitosin bekerja dan ASInya mengalir. Sebaliknya perasaan negatif seperti stres dapat menghambat reflek oksitosin dan menghentikan ASI mengalir. Payudara tampak berhenti memproduksi ASI, padahal payudara tetap memproduksi ASI, tetapi tidak dapat mengalir keluar. Kondisi ini biasanya bersifat sementara, ibu hanya membutuhkan dukungan dan kenyamanan agar ibu merasa tenang, Jika bayinya tetap menyusu, maka ASInya akan mengalir kembali (Selasi, 2011).

\section{KESIMPULAN}

Penelitian ini menghasilkan empat kategori yang menggambarkan pengalaman ibu bekerja dalam memberikan ASI eksklusif. 
Kategori tersebut yaitu pengetahuan ibu tentang asi eksklusif, ASI perah, motivasi ibu dalam pemberian ASI eksklusif, upaya yang dilakukan ibu dalam memberikan ASI eksklusif, dukungan keluarga dan dukungan tempat kerja. Hasil penelitian ini dapat menjadi gambaran bagi tenaga kesehatan untuk dapat meningkatkan promosi kesehatan tentang ASI eksklusif ke berbagai tempat kerja dan diharapkan agar tempat bekerja dapat memfasilitasi ibu menyusui dalam memberikan ASI eksklusif agar cakupan ASI eksklusif meningkat.

\section{KEPUSTAKAAN}

Aksu,H., Kucuk,M., Duzgun,G. (2011). The effect of postnatal breastfeeding education/ support offered at home 3 days after delivery on breastfeeding duration and knowladge: a randomized trial. The journal of maternal-fetal and neonatal medicine. 24(2).

Amin, R.M., Said, Z.M., Sutan,R., Shah, A.A., Darus,A., \& Shamsuddin, K. (2011).

Work releated determinants of breasfeeding discountinuation among employed mothers in Malaysia. International breasfeeding journal.

Bidang Ketenagakerjaan dan Ketransmigrasian. (2012). Rencana pembangunan jangka panjang 2010-2025. Kementrian Tenaga Kerja dan Transmigrasi Republik Indonesia. From www.depnakertrans.go.id

Chen,Y.C., Wu,Y.C., \& Chie,W.C. (2006). Effect of work-releated factors on the breasfeeding behavior manufacturer: a cross-sectional survey. Biomed Central Public Health.

Fikawati S dan Syafiq A. (2010). Kajian Implementasi dan Kebijakan Air Susu Ibu Eksklusif dan Inisiasi Menyusui Dini di Indonesia. Makara Kesehatan, 14 (1): 17-24, Juni 2010
Ip,S.,dkk. (2007). Breasfeeding and maternal and infant health outcomes in developed countries. Evid rep technol asses. 153.

Kemenkes RI. (2013). Profil Kesehatan Indonesia 2012. Jakarta: Kemenkes

Kemenkes RI. (2018). Data dan Informasi: Profil Kesehatan Indonesia 2017. Jakarta: Kemenkes

Peraturan Daerah Provinsi Lampung. (2014). Nomor 17 Tentang Pemberian Air Susu Ibu Eksklusif.

Peraturan Menteri Kesehatan Republik Indonesia. (2013). Nomor 15 Tentang Tata Cara Penyediaan Fasilitas Khusus Menyusui Dan / Atau Memerah Air Susu $\mathrm{Ibu}$

Poedianto. (2002). Kiat sukses menyusui. Jakarta: aspirasi pemuda.

Solis,B., \& Breakenridge,D. (2009). Praise for putting the public back in public relation: how social media is reinventing the aging business of PR.FT Press.

Roesli, Utami. (2008). Inisiasi menyusu dini plus ASI eksklusif. Jakarta : Pustaka Bunda.

Sentra Laktasi Indonesia/ Selasi. (2011). Pelatihan konseling menyusui modul 40 jam WHO/UNICEF

Setiowati T. (2011). Hubungan Faktor-faktor Ibu dengan Pelaksanaan Pemberian ASI Eksklusif pada Bayi 6 - 12 Bulan di Desa Cidadap Wilayah Kerja Puskesmas Pegaden Barat Kabupaten Subang Periode Januari - Juli 2011. Jurnal Kesehatan Kartika. 10 (5): 10 - 17, Juli 2011

Undang - Undang Republik Indonesia. (2009). Nomor 36 tentang Kesehatan

Undang - Undang Republik Indonesia. (2003). Nomor 13 Tentang Ketenagakerjaan

UNICEF. (2012). Mari Jadikan ASI Eksklusif Prioritas Nasional. Pusat Media. UNICEF. Diakses 19 Maret 2016. http://www.unicef.org/Indonesia/id/medi a_19265.html

World Health Organization. (2003). Global strategy for infant and young child feeding. 